\title{
Impact of Climate Change on Global Food Production System
}

\author{
Authors: Khanal V ${ }^{\circledR}$, MPH, Curtin University, Australia. \\ Neupane D, MPH, University of Southern Denmark \\ OCorrespondence: Vishnu Khanal \\ School of Public Health \\ Curtin University, Australia. \\ khanal.vishnu@gmail.com
}

\section{Introduction}

Many factors affect the global food production system. As Agriculture system depends on the climatic temperature, soil quality and precipitation, it is easily affected by climate change (McMichael, Powles, Butler, \& Uauy, 2007). It is recorded that last decade of $20^{\text {th }}$ century was the hottest decade (Bunyavanich, Landrigan, McMichael, \& Epstein, 2003). The hot seasons and increase in temperature have raised concern about the issue of climate change though the efforts to focus on climate change started in the late 1980s (Bunyavanich et al., 2003). It is now realized that climate change is the biggest potential threat for the world in this century (Ford, Berrang-Ford, King, \& Furgal, 2010) . One of the major issues that current world is concerned about is impact of climate change on food production system (Schmidhuber \& Tubiello, 2007). Therefore, this paper examines the impacts of climate change on food production system.

\section{Evidences from literature review}

This section will give an over view of the causes of climate change, positive and negative effects of climate change on global food production system.

\subsection{Causes of climate change}

Greenhouse gases are the major cause of the climate change. These gases include water vapour, carbon dioxide, methane, nitrous oxide, fluorine compound (SF6, 2PFCs) (National Aeronautics and Space Administration, 2011). These gases are largely emitted by the industries from the developed countries (St Louis \& Hess, 2008). Fossil fuel combustion is another reason for greenhouse gas emission (Haines, Kovats, Campbell-Lendrum, \& Corvalan, 2006). In addition, agriculture and food production sector is a contributor for greenhouse emission (McMichael et al., 2007). For example; in Australia, agricultural sector is responsible for $16 \%$ of national net emission of green house gases (Coveney, Sulda, \& Bentley, 2010).

\subsection{Effects of Climate change on food production system}

Increase in temperature, change in precipitation, draught, increase in extent and frequency of extreme weather situation, ocean warming and acidification, and increase in concentration of atmospheric carbon dioxide are the major climate change factors that have effect on food production and agriculture system (Miraglia et al., 2009; Tirado, Clarke, Jaykus, McQuatters-Gollop, \& Franke, 2010). Other factors that are aggravated by climate change and have significant impact on food production system are increase in pests and degrading soil quality (Miraglia et al., 2009). As a result of various greenhouse gas emissions, it is estimated that at the end of this century total temperature will be increased by $3.4^{\circ} \mathrm{C}$ (McMichael et al., 2007). This will bring about a change in hydrological system; ranging effects from extreme precipitation to draught. This increase will also give synergistic effects to the extreme weather conditions, precipitation and draught (Tirado et al., 2010; United Nations Standing Committee on Nutrition, 2010).

\subsubsection{Positive effects on productions system}

Crops in temperate regions will respond positively due to increased atmospheric temperature and increased carbon dioxide (National Aeronautics and Space Administration, 2011). This will cause an increased agriculture production in the certain regions of United States, Europe and Asia (McMichael et al., 2007; Miraglia et al., 2009; US Environmental Protection Agency, 2011). Similarly, McMichael and colleagues (McMichael et al., 2007) in their review showed that by 2020 there will be an increase in $20 \%$ of food production in east and South East Asia. However, climate change will greatly alter the zones where crops can be grown best and also a change will occur in natural vegetation (National Aeronautics and Space Administration, 2011). Quantification of positive impacts of climate change on fishery, marine food production and poultry industry have not been found in the literatures reviewed in this paper.

\subsubsection{Adverse effects of climate change on food production system}

Though climate change includes a range of manifestations, the estimations and modelling have been primarily illustrated in relation to the global temperature change and its potential impact on future of the world (United 
Nations Standing Committee on Nutrition, 2010). It is estimated that in the first decade of the twenty first century due to increase in carbon dioxide and slight rise in temperate within the threshold there will be increase in production; mainly for the cereal grains (Miraglia et al., 2009; US Environmental Protection Agency, 2011). Literatures are not describing effects during this time period in Africa region, which primarily is considered to be vulnerable in recent future (McMichael et al., 2007; United Nations Standing Committee on Nutrition, 2010). It shows a major gap in estimate to show overall effect on global or regional food production.

Amount of reduction in food production will differ based on the regions. McMichael and colleagues (McMichael et al., 2007) in their review showed that by 2020 there be decreased in food production by $30 \%$ in Central and South Asia and more importantly reduction could go as high as $50 \%$ in some African countries due to climate change. Further estimate says that by 2060 developing countries will face a total decline of 9 to $11 \%$ in their crop production due to climate change (Pary M, 2007).This estimates seems quite less than the former estimate done by Mc Micheal and Colleagues (McMichael et al., 2007; Pary M, 2007). It shows that estimates are not precise, coherent and detailed. Hence, it is not easy to look at the exact amount of decrease in food production in each of the developing and developed region.

There are several explanations about the reduction in crop production due to climate change. The simple three are; increase in pests due to increase in temperate; rapid disintegration of organic matter of the soil into inorganic component and ultimately changing the soil in to barren land; and adversely affecting the infrastructure set for irrigation (Omann, Stocker, \& Jager, 2009; St Louis \& Hess, 2008). The predicted effect on sea coasts is rise in sea level will increase salination of ground water leading to desertification and lower productivity of land (Tirado et al., 2010).

Marine food production system is also estimated to be adversely affected. Though it is mentioned in several reviews but comprehensive statistical modelling or estimates were not found for quantifying the reduction (McMichael et al., 2007; Miraglia et al., 2009). Animal production system is another component of the food production system. Miraglia and colleague (Miraglia et al., 2009) in their review predict that there will a minimal impact on animal production system. As animal has better coping mechanisms with temperature than plants, this justification seems valid. This explanation seems further justifiable that in one side there will an increase in summer temperature that will adversely affect the animal food production but in other side, increase in winter temperature will facilitate such food products leaving overall balance in the production (Miraglia et al., 2009).

Another important aspect of climate change is disproportionate impact on different groups. Though this change occur all over the world, impact of the climate will heat the poorest countries with hardest impacts (St Louis $\&$ Hess, 2008). An estimate in 2000 showed that $2.4 \%$ cases of diarrheal disease were attributable to climate change ( $\mathrm{St}$ Louis \& Hess, 2008). The same estimate further added that 5.5 million DALYs lost could be attributable to climate change in South Asia and Africa region only. Concentrating on nutrition issues; malnutrition is the major issue that will be aggravated by the impact of climate change due to reduced food production. Vast majority of population in the poorest part of the world depend on subsistence agriculture economy (St Louis \& Hess, 2008). The majority of the crops are sensitive to change in temperature, even in very small scale and hence resulting into less food production (St Louis \& Hess, 2008). Once there is shortage of rain, or change in pattern of raining or famine or draught, there is likely to result into less food production or loss of productivity of the land. All of these factors ultimately will hit the poorest people making their lives harder and hence resulting into under nutrition (St Louis \& Hess, 2008). Moreover, as the climate change hits the food production system, food price of healthy foods will be increased by $25 \%$ to $150 \%$ by 2060 and hence, $200-600$ million more people will be suffering from hunger (Coveney et al., 2010; United Nations Standing Committee on Nutrition, 2010).

It must be noted that though all of the authors acknowledged the impact of climate change into food production and nutrition, it has not been clearly detailed how climate change-disease-food production system affect each other and what will be the cumulative effects of this interaction on global food production (Miraglia et al., 2009; Schmidhuber \& Tubiello, 2007; St Louis \& Hess, 2008; United Nations Standing Committee on Nutrition, 2010).

However, Devereux and Edwards (Devereux \& Edwards, 2004) in their review contradict with above forecasts and they also claimed that overall food production will remain same. They also suggested that forecasts should be done cautiously enough to reach a scientific consensus. But in the same review they agreed that the developing countries will face the worst effects. This can also be justified by the projection that if nothing is done, three African countries Chad, Nigeria and Zambia will lose entire farming sector by 2100 (Devereux \& Edwards, 2004). Hence, United Nation's claim that global food production will decrease seems more convincing (United Nations Standing Committee on Nutrition, 2010).

Developed countries are not free from the potential impact of the climate change. Within these countries, aboriginal and poor communities are the most vulnerable groups (Ford et al., 2010). Moreover, effect of costal mass displacement will also ultimately hit these countries adversely. United States of America, the biggest food producer, will suffer a decrease in food production from the climate change effects on its grain-area (US Environmental 
Protection Agency, 2011).

One fourth of the global population lives in the sea coast, if sea level is risen then there will massive movement of the human from one place to other and having a massive impact on food production and supply system (Tirado et al., 2010). It may yield into short term or long term food shortage, establishment of new residential areas in agricultural places or massive scarcity of food items in some part of the world (Tirado et al., 2010).

Other impact on public health nutrition is can be attributable to the disease and heath consequences. Climate change impacts on health of the people which ultimately hits the nutrition status of the population (United Nations Standing Committee on Nutrition, 2010). Hence, the result will be decreased labour force. Decreased labour force will result into the decreased food production as food production system is labour intensive (Haines et al., 2006; United Nations Standing Committee on Nutrition, 2010).

\subsection{Gaps in current knowledge}

Authors suggest that to estimation of full impact of the climate change on food safety needs 50 years' assessment time (Miraglia et al., 2009). At this point of time, there is no time to wait for such a comprehensive impact assessment. Hence assumptions and statistical modelling are now relied for estimates (Miraglia et al., 2009). As the concern is growing, these modellings and estimates are being made in ad-hoc basis which have resulted into varied estimates (Ford et al., 2010; LB Ford, J D Ford, \& J Paterson, 2011). One of the major drawback, as discussed by Devereux and Edwards, seems more plausible, that these estimates underestimated the technological changes, and isolate the climate change in its total effect only and rarely consider that other individual and societal efforts and technological contribution in food production system (Devereux \& Edwards, 2004; Omann et al., 2009). The cited literature are also not able to predict impact of increase in pest population and degrading soil quality, and impact of human population displacement due to climate change on food production system (McMichael et al., 2007; Miraglia et al., 2009; Schmidhuber \& Tubiello, 2007). Other gaps are described in related subheading in this review.

\section{Conclusion}

Climate change is inevitable threat for global food production and food security. Though statistical evidences are not elaborative or enough for all of the counties, evidences and estimates are enough to show the possible risks from climate change (Miraglia et al., 2009; United Nations Standing Committee on Nutrition, 2010). Climate change through its variety of manifestation will reduce agriculture and marine (including fishery) food production, and possibly affect adversely to poultry and animal food sector as well. The effect of climate change will hit the entire world but it will hit adversely to the poorest of the poor with hardest impact (McMichael et al., 2007). Technological advances, adaptation measures by countries at local and global level, and contribution from societies and individual should be undertaken as soon as possible (St Louis \& Hess, 2008; United Nations Standing Committee on Nutrition, 2010). Control of causes of climate changes are not easy but opportunities are there to reduce emission of greenhouse gases, mitigate the effects and provide safety net to the vulnerable populations (Devereux \& Edwards, 2004). Moreover, there are chances to mitigate the adverse effects on food production system and human population (Devereux \& Edwards, 2004; Tirado et al., 2010).

\section{References}

1. Bunyavanich, S., Landrigan, C. P., McMichael, A. J., \& Epstein, P. R. (2003). The impact of climate change on child health. Ambul Pediatr, 3(1), 44-52. Retrieved from http://www.ncbi.nlm.nih.gov/pubmed/12540254

2. Coveney, J., Sulda, H., \& Bentley, M. (2010). An investigation of the ways in which public health nutrition policy and practices can address climate change. Public Health Nutrition, 13(3), 304-313. Retrieved from <Go to ISI>://000274810700002. doi:10.1017/S1368980009990334

3. Devereux, S., \& Edwards, J. (2004). Climate change and food security. Ids Bulletin-Institute of Development Studies, 35(3), 22-+. Retrieved from <Go to ISI >:// 000223148700004

4. Ford, J. D., Berrang-Ford, L., King, M., \& Furgal, C. (2010). Vulnerability of Aboriginal health systems in Canada to climate change. Global Environmental Change-Human and Policy Dimensions, 20(4), 668-680. Retrieved from <Go to ISI>://000284436800014. doi:10.1016/j.gloenvcha.2010.05.003

5. Haines, A., Kovats, R. S., Campbell-Lendrum, D., \& Corvalan, C. (2006). Climate change and human health: Impacts, vulnerability and public health. Public health, 120(7), 585-596. Retrieved from <Go to ISI>:// 000239272000003. doi:10.1016/j.puhe.2006.01.002

6. LB Ford, J D Ford, \& J Paterson. (2011). Are we adapting to climate change? Global Environmental Change, 25, 25-33. doi:10.1016/j.gloenvcha.2010.09.012

7. McMichael, A. J., Powles, J. W., Butler, C. D., \& Uauy, R. (2007). Energy and health 5 - Food, livestock production, energy, climate change, and health. Lancet, 370(9594), 1253-1263. Retrieved from <Go to ISI $>$ :// 000250091900026. doi:10.1016/S0140-6736(07)61256-2

8. Miraglia, M., Marvin, H. J. P., Kleter, G. A., Battilani, P., Brera, C., Coni, E., et al. (2009). Climate change and food safety: An emerging issue with special focus on Europe. Food and Chemical Toxicology, 47(5), 10091021. Retrieved from <Go to ISI $>$ ://000265970600011. doi:10.1016/j.fct.2009.02.005

9. National Aeronautics and Space Administration. (2011). 
Global Climate Change. Retrieved from http:// climate.nasa.gov/causes/

10. Omann, I., Stocker, A., \& Jager, J. (2009). Climate change as a threat to biodiversity: An application of the DPSIR approach. Ecological Economics, 69(1), 24-31. Retrieved from <Go to ISI $>$ ://000271359400004. doi:10.1016/ j.ecolecon.2009.01.003

11. Pary M. (2007). The Implications of Climate Change for Crop Yields, Global Food Supply and Risk of Hunger. SAT eJournal, 4(1), 1-44. Retrieved from http:// www.icrisat.org/journal/SpecialProject/sp14.pdf

12. Schmidhuber, J., \& Tubiello, F. N. (2007). Global food security under climate change. Proceedings of the National Academy of Sciences of the United States of America, 104(50), 19703-19708. Retrieved from <Go to ISI $>$ ://000251752200012. doi:10.1073/pnas.0701976104

13. St Louis, M. E., \& Hess, J. J. (2008). Climate change: impacts on and implications for global health. American journal of preventive medicine, 35(5), 527-538. Retrieved from http://www.ncbi.nlm.nih.gov/pubmed/18929979. doi:S0749-3797(08)00688-0 [pii]10.1016/j.amepre.2008. 08.023

14. Tirado, M. C., Clarke, R., Jaykus, L. A., McQuattersGollop, A., \& Franke, J. M. (2010). Climate change and food safety: A review. Food Research International, 43(7), 1745-1765. Retrieved from <Go to ISI >:// 000282860700003. doi:10.1016/j.foodres.2010.07.003

15. United Nations Standing Committee on Nutrition. (2010). Climate Change and Nutrition Security. Retrieved from http://www.unscn.org/en/ announcements/nutrition_informations_resources/ ?id=389

16. US Environmental Protection Agency. (2011). Climate Change. Retrieved from http://www.epa.gov/ climatechange/effects/agriculture.html 